Check for updates

Cite this: RSC Adv., 2018, 8, 30455

Received 9th July 2018

Accepted 12th August 2018

DOI: $10.1039 / c 8 r a 05861 j$

rsc.li/rsc-advances

\section{Green synthesis of surface-passivated carbon dots from the prickly pear cactus as a fluorescent probe for the dual detection of arsenic(III) and hypochlorite ions from drinking water}

\begin{abstract}
K. Radhakrishnan (iD and P. Panneerselvam (DD*
Efforts were made to develop a simple new approach for the green synthesis of surface-passivated carbon dots from edible prickly pear cactus fruit as the carbon source by a one-pot hydrothermal route. Glutathione (GSH) was passivated on the surface of the CDs to form a sensor probe, which exhibited excellent optical properties and water solubility. The prepared sensor was successfully characterized by UV-visible spectrophotometry, fluorescence spectrophotometry, Fourier transform infrared spectroscopy (FT-IR), X-ray diffraction (XRD), scanning electron microscopy (SEM), and transmission electron microscopy (TEM). The simple sensing platform developed by the GSH-CDs was highly sensitive and selective with a "turn-off" fluorescence response for the dual detection of $\mathrm{As}^{3+}$ and $\mathrm{ClO}^{-}$ions in drinking water. This sensing system exhibited effective quenching in the presence of $\mathrm{As}^{3+}$ and $\mathrm{ClO}^{-}$ions to display the formation of metal complexes and surface interaction with an oxygen functional group. The oxygen-rich GSH-CDs afforded a better selectivity for $\mathrm{As}^{3+} / \mathrm{ClO}^{-}$ions over other competitive ions. The fluorescence quenching measurement quantified the concentration range as 2-12 nM and 10-90 $\mu \mathrm{M}$ with the lower detection limit of $2.3 \mathrm{nM}$ and $0.016 \mu \mathrm{M}$ for the detection of $\mathrm{As}^{3+}$ and $\mathrm{ClO}^{-}$ions, respectively. Further, we explored the potential applications of this simple, reliable, and cost-effective sensor for the detection of $\mathrm{As}^{3+} / \mathrm{ClO}^{-}$ions in environmental samples for practical analysis.
\end{abstract}

\section{Introduction}

Arsenic $\left(\mathrm{As}^{3+}\right)$ and hypochlorite ions $\left(\mathrm{ClO}^{-}\right)$have shown an extensive range of poisonous action that can adversely affect the water quality and threaten the public health and the environment. Arsenic contamination has been found to have significantly increased in the environment as a result of industrialization, urbanization, the use of additives in poultry feed, and by agricultural activity. ${ }^{1-3}$ The World Health Organization announced the presence of $\mathrm{As}^{3+}$ ions in natural water beyond $10 \mathrm{ppb}$ as a global environmental problem, which has attracted the attention of the research community. The U.S. Environmental Protection Agency and International Association for Research into Cancer have classified $\mathrm{As}^{3+}$ as a Group A and Category 1 human carcinogen. ${ }^{4-6}$ As the source of $\mathrm{As}^{3+} / \mathrm{ClO}^{-}$ions is widespread, they can be easily circulated into ecological processed through our diets. ${ }^{7-10}$ Arsenic accumulation in the human body affects the lungs, kidneys, bladder, and liver and also causes various cancers. ${ }^{11,12}$ Similarly, exposure to hypochlorite ions leads to damage of red

Department of Chemistry, SRM Institute of Science and Technology, Kattankulathur-603 203, Tamil Nadu, India. E-mail: panneerselvam.pe@ktr. srmuniv.ac.in; panneerchem82@gmail.com; Tel: +919688538842 blood cells, neuron degeneration, and lung injury. ${ }^{13-16}$ Further, $\mathrm{As}^{3+} / \mathrm{ClO}^{-}$ions cause a severe health risk of cardiovascular and respiratory diseases. ${ }^{17-20}$ Therefore, it is mandatory and a pressing need for the global research community to develop a user-friendly, selective, sensitive, and reliable method for the detection of $\mathrm{As}^{3+} / \mathrm{ClO}^{-}$ions.

Many analytical techniques have been developed for the accurate determination of $\mathrm{As}^{3+} / \mathrm{ClO}^{-}$ions. Trace levels of $\mathrm{As}^{3+}$ ions have been quantitatively detected by inductively coupled plasma mass spectroscopy (ICP-MS), inductively coupled plasma atomic emission spectrometry (ICP-AES), atomic fluorescence spectrometry (AFS), and atomic absorption spectrometry (AAS). ${ }^{21-25}$ The common analytical methods used for the accurate detection of $\mathrm{As}^{3+} / \mathrm{ClO}^{-}$ions are chemosensors, biosensors, and iodometric and polarographic methods. ${ }^{26-34}$ Though these techniques are very qualitative and quantitative, yet they are limited to expensive instrumentation, inconvenient analytical methods, tedious material preparation procedures, and are time consuming. Recently, fluorometric and colorimetric sensors have exhibited an instant response and reusability. Although, they are powerful tools for the potential monitoring of heavy metal ions in real time, the preparation methodology of nanomaterials and functionalization of the utilized organic 
probe are tedious and limit their wide application. Indeed, a novel fluorescent sensor is still required for the practical detection of $\mathrm{As}^{3+} / \mathrm{ClO}^{-}$ions in environmental samples.

In the past decade, carbon dots have been emerged as excellent fluorescent probes with unique features. Some of the merits are their eco-friendly nature, water solubility, chemical stability, low toxicity, and biocompatibility. These interesting features of fluorescent CDs have drawn the attention of the scientific community for their application in imaging, diagnosis, catalysis, and energy conversion. ${ }^{35-39}$ Fortunately, carbon dots possess a strong optical response, narrow emission peak, and broad excitation spectra, which give them an obvious advantage over other conventional dyes with challenging properties, like a narrow excitation wave length, broad emission band, and low fluorescence intensity. ${ }^{40-42}$ The prime limitation of CDs is their unsatisfactory sensitivity or fluorescence intensity for the detection of target species based on their poor functionalization. ${ }^{43}$ The sensitivity of the CDs can, however, be apparently improved by surface modification, which comprises surface functionalization and heteroatom doping to afford new classes of CDs. Such surface-passivated CDs have shown improved sensitivity, specificity, an enhancement in their fluorescent efficiency and also improved active sites for better sensing platform performance. ${ }^{44}$ In regards environmental protection, many eco-friendly precursors have been developed to synthesize CQDs from hair, banana juice, pee pollen, and winter melon, etc. $^{45-49}$ These sources are highly desirable for achieving a simple, economical, and green synthesis procedure for the preparation of fluorescent CQDs. The application of biomass to prepare carbon nanomaterials has been one strong trend to synthesize a surface-passivated material to improve the selectivity by functionalization and enhanced sensitivity to recognize certain analytical species.

Herein, we report a one-pot synthetic route for the preparation of surface-passivated oxygen-rich GSH-CDs as a multifunctional sensor for the selective and sensitive detection of $\mathrm{As}^{3+} / \mathrm{ClO}^{-}$ions in drinking water. The GSH-CDs were successfully synthesized from prickly pear cactus as a carbon source and glutathione passivation to render surface-activated carboxylic groups, amine groups, and hydroxyl groups as sensing probes for the sensitive detection of $\mathrm{As}^{3+} / \mathrm{ClO}^{-}$ions. In addition, the developed green synthesis procedure and sample preparation did not require any tedious conditions. This aspect promotes simplicity, specificity, and also a sensitive response in the $\mathrm{pH}$ range of 6 to 8 for the quantitative analysis of the target ions. The quenching of the bright blue emission of the sensing system was used as a signaling unit and its fluorescence intensity was a direct read-out of the specificity in the chelation of $\mathrm{As}^{3+}$ / $\mathrm{ClO}^{-}$ions. To the best of our knowledge, this was the first attempt to propose surface-passivated fluorescent carbon dots as a fluorescent probe for the sensing of $\mathrm{As}^{3+} / \mathrm{ClO}^{-}$ions. The sensing mechanism was stated showing the feasibility for dual detection, while the recovery study highlighted the selectivity of the sensor to $\mathrm{As}^{3+}$ and $\mathrm{ClO}^{-}$ions.

\section{Experimental section}

\subsection{Chemicals and materials}

The prickly pear cactus was collected from the bare lands near Potheri mount. Tris(hydroxymethyl) methyl amino methane, glutathione, L-cysteine, sodium borohydride $\left(\mathrm{NaBH}_{4}\right)$, and the salts of various metal ions $\left(\mathrm{Ag}^{+}, \mathrm{K}^{+}, \mathrm{Ca}^{2+}, \mathrm{Cu}^{2+}, \mathrm{Ni}^{2+}, \mathrm{Ba}^{2+}, \mathrm{Pb}^{2+}\right.$, $\mathrm{Hg}^{2+}, \mathrm{Cd}^{2+}, \mathrm{Co}^{2+}, \mathrm{Fe}^{2+}, \mathrm{As}^{3+}, \mathrm{Fe}^{3+}, \mathrm{Cl}^{-}, \mathrm{ClO}^{-}, \mathrm{Br}^{-}, \mathrm{I}^{-}, \mathrm{SCN}^{-}$, $\mathrm{NO}_{2}{ }^{-}, \mathrm{PO}_{4}{ }^{3-}, \mathrm{H}_{2} \mathrm{PO}_{4}{ }^{-}, \mathrm{SO}_{4}{ }^{2-}, \mathrm{ONOO}^{-}, \cdot \mathrm{OH}$, and $\mathrm{O}_{2}{ }^{--}$), were purchased from Alfa Aesar. The chemicals and reagents used in this experiment were of analytical grade and were used without further treatment. Ultrapure water (Milli-Q water), drinking water, and tap water were used in preparation of the solutions.

\subsection{General methods}

UV-visible spectroscopic analyses were recorded on a Shimadzu UV-2600 spectrophotometer. The fluorescence spectra of GSHCDs were measured on a HORIBA JOBIN-YVON Fluoromax-4 spectrofluorometer. FT-IR spectra were measured using an Agilent Resolution Pro FT-IR spectrometer. X-Ray diffraction (XRD) patterns were recorded by PAN analytical X'pert power diffractometer using $\mathrm{Cu} \mathrm{K} \alpha$ radiation as the source for excitation. Transmission electron microscopic (TEM) images of the sample were analyzed on a JEOL/JEM-2100 at an operating voltage of $2000 \mathrm{kV}$. The fluorescence quenching lifetime of the GSH-CDs was examined using a JOBIN-YVON M/S.

\subsection{One-pot synthesis of GSH-CDS}

Glutathione-passivated carbon dots were synthesized by a onestep hydrothermal method. Briefly, $0.350 \mathrm{~g}$ prickly pear cactus juice was added to a $1: 1$ solution of water : ethanol $(\mathrm{v} / \mathrm{v})$. To the above reaction mixture, $0.300 \mathrm{~g}$ of glutathione was added and refluxed for $1 \mathrm{~h}$. The final reaction mixture was packed into a Teflon-lined autoclave and heated at $180{ }^{\circ} \mathrm{C}$ for a period of $12 \mathrm{~h}$. The obtained brownish product was cooled to room temperature naturally, and then larger nanoparticles are removed by filtration using a $0.22 \mu \mathrm{m}$ filter membrane. Finally, the suspension was centrifuged at $12000 \mathrm{rpm}$ for about $30 \mathrm{~min}$ to obtain a yellowish supernatant as a final product. It was then refrigerated at $4{ }^{\circ} \mathrm{C}$ for further characterization and analysis.

\subsection{Detection of $\mathrm{As}^{3+} / \mathrm{ClO}^{-}$ions with GSH-CDs}

$\mathrm{As}^{3+}$ ions were detected in optimum conditions at room temperature in tris-HAc buffer medium. Typically, $10 \mu \mathrm{L} \mathrm{GSH}-$ CDs was added into $1000 \mu \mathrm{L}$ of tris-HAc buffer $(10 \mathrm{mM}, \mathrm{pH}$ 7.4). The required concentrations of $\mathrm{As}^{3+} / \mathrm{ClO}^{-}(0-30 \mathrm{nM} / 0-200$ $\mu \mathrm{M})$ ions were prepared from the stock solution via $20 \mu \mathrm{L}$ used for the analysis. The sample was diluted with drinking water to obtain a final volume of $3 \mathrm{~mL}$. The reaction mixture of $\mathrm{As}^{3+}$ ions was incubated for $2 \mathrm{~min}$ at room temperature and then the emission intensity was analyzed, where the response of $\mathrm{ClO}^{-}$ ions was recorded immediately. The fluorescence quenching intensity of the GSH-CDs was recorded to identify the selectivity and sensitivity for $\mathrm{As}^{3+} / \mathrm{ClO}^{-}$ions in the drinking water. 


\subsection{Detection of $\mathrm{As}^{3+} / \mathrm{ClO}^{-}$ions in real samples}

The environmental water samples, including tap, pond, river, and industrial waste water, were collected from various sources near our laboratory and filtered through a $0.22 \mu \mathrm{m}$ filter to remove the solid impurities. The purified water $(100 \mu \mathrm{L})$ was mixed with tris-HAc buffer $(1000 \mu \mathrm{L})$ and then the preferred concentration of $\mathrm{As}^{3+} / \mathrm{ClO}^{-}$ions was spiked into the above mixture, as shown in Tables 3 and 4 . GSH-CDs $(10 \mu \mathrm{L})$ were added into the above reaction mixture, which was then further diluted with water to obtain a final volume of $3 \mathrm{~mL}$. The fluorescence quenching intensity of GSH-CDs was recorded.

\subsection{Quantum yield determination}

The quantum yield (QY) of the surface-passivated GSH-CDs were investigated with an aqueous solution of quinine sulfate in $0.1 \mathrm{M} \mathrm{H}_{2} \mathrm{SO}_{4}$ as a reference dye, with a QY of $0.54 \%$ obtained at an excitation wavelength of $370 \mathrm{~nm}$. The integrated intensities and absorbance of GSH-CDs were compared with quinine sulfate to measure the quantum yield following equation: ${ }^{50}$

$$
Q_{x}=Q_{\text {std }}\left(I_{x} / I_{\text {std }}\right)\left(\eta_{x}^{2} / \eta_{\text {std }}^{2}\right)\left(A_{\text {std }} / A_{x}\right)
$$

where, $Q_{x}$ and $Q_{\text {std }}$ are the quantum yields of GSH-CDs and quinine sulfate; $\eta_{x}{ }^{2}$ and $\eta_{\text {std }}{ }^{2}$ are he refractive indexes of water and $\mathrm{H}_{2} \mathrm{SO}_{4} ; I_{x}$ and $I_{\text {std }}$ are the integrated emission area; and $A_{x}$ and $A_{\text {std }}$ are their optical densities of GSH-CDs and quinine sulfate dye. The quantum yield of GSH-CDs was measured to be $12.7 \%$.

\section{Results and discussion}

The CDs were synthesized from prickly pear cactus fruits by a one-pot hydrothermal procedure. Since, the prickly pear cactus encloses numerous organic acids (malonic, glutaric, malic, citric, phobic, and piscidic acids) and amino acids

Table 1 Various fluorescent sensors for the detection of $\mathrm{As}^{3+}$

\begin{tabular}{|c|c|c|c|c|}
\hline Materials & Readout mechanism & Working range (M) & LOD & Ref. no. \\
\hline CdTe QD & Turn off & $2 \mathrm{nM}$ to $0.5 \mu \mathrm{M}$ & $2 \mathrm{nM}$ & 55 \\
\hline Thiol/CQDs & Turn off & $5-100 \mathrm{ppb}$ & $0.086 \mathrm{ppb}$ & 56 \\
\hline $\mathrm{CdTe} / \mathrm{ZnS}$ & Turn on & $1 \times 10^{-11}$ to $1 \times 10^{-6}$ & $1.3 \times 10^{-12}$ & 58 \\
\hline GSH/CQDs & Turn off & $2-25 \times 10^{-9}$ & $2.3 \times 10^{-9}$ & Present work \\
\hline
\end{tabular}

Table 2 Various fluorescent sensors for the detection of $\mathrm{ClO}^{-}$

\begin{tabular}{|c|c|c|c|c|}
\hline SiQDs & Turn off & $0.01 \times 10^{-6}$ to $50 \times 10^{-6}$ & $0.01 \times 10^{-6}$ & 59 \\
\hline Glucose-GCDs & Turn off & $0.5 \times 10^{-6}$ to $1000 \times 10^{-6}$ & $0.3 \times 10^{-6}$ & 60 \\
\hline $\mathrm{MoS}_{2}$ QDs & Turn off & $5 \times 10^{-6}$ to $500 \times 10^{-6}$ & $0.5 \times 10^{-6}$ & 62 \\
\hline Ethylenediamine, citric acid CDs & Turn off & $10 \times 10^{-6}$ to $140 \times 10^{-6}$ & $4 \times 10^{-6}$ & 63 \\
\hline GSH/CDs & Turn off & $10 \times 10^{-6}$ to $200 \times 10^{-6}$ & $0.016 \times 10^{-6}$ & Present work \\
\hline
\end{tabular}

Table 3 Detection of $\mathrm{As}^{3+}$ in environmental water samples

\begin{tabular}{lccrc}
\hline Samples & Spiked $\left[\mathrm{As}^{3+}\right] /(\mathrm{nM})$ & Found $\mathrm{As}^{3+} /(\mathrm{nM})$ & Recovery $(\%)$ & \multicolumn{2}{c}{} \\
\hline Tap water & 3 & 2.97 & 99 & 1.12 \\
River water & 8 & 7.89 & 98.62 & 1.32 \\
Pond water & 13 & 12.95 & 99.62 & 2.17 \\
Industrial wastewater & 18 & 18.13 & 100.72 & 1.18
\end{tabular}

Table 4 Detection of $\mathrm{ClO}^{-}$in environmental water samples

\begin{tabular}{|c|c|c|c|c|}
\hline Samples & Spiked $\left[\mathrm{ClO}^{-}\right] /(\mu \mathrm{M})$ & Found $\mathrm{ClO}^{-} /(\mu \mathrm{M})$ & Recovery (\%) & $\operatorname{RSD}(\%)$ \\
\hline Tap water & 5 & 5.02 & 100.4 & 2.14 \\
\hline River water & 10 & 9.97 & 99.67 & 1.56 \\
\hline Pond water & 15 & 14.83 & 98.92 & 1.36 \\
\hline Industrial waste water & 20 & 19.77 & 98.84 & 2.1 \\
\hline
\end{tabular}



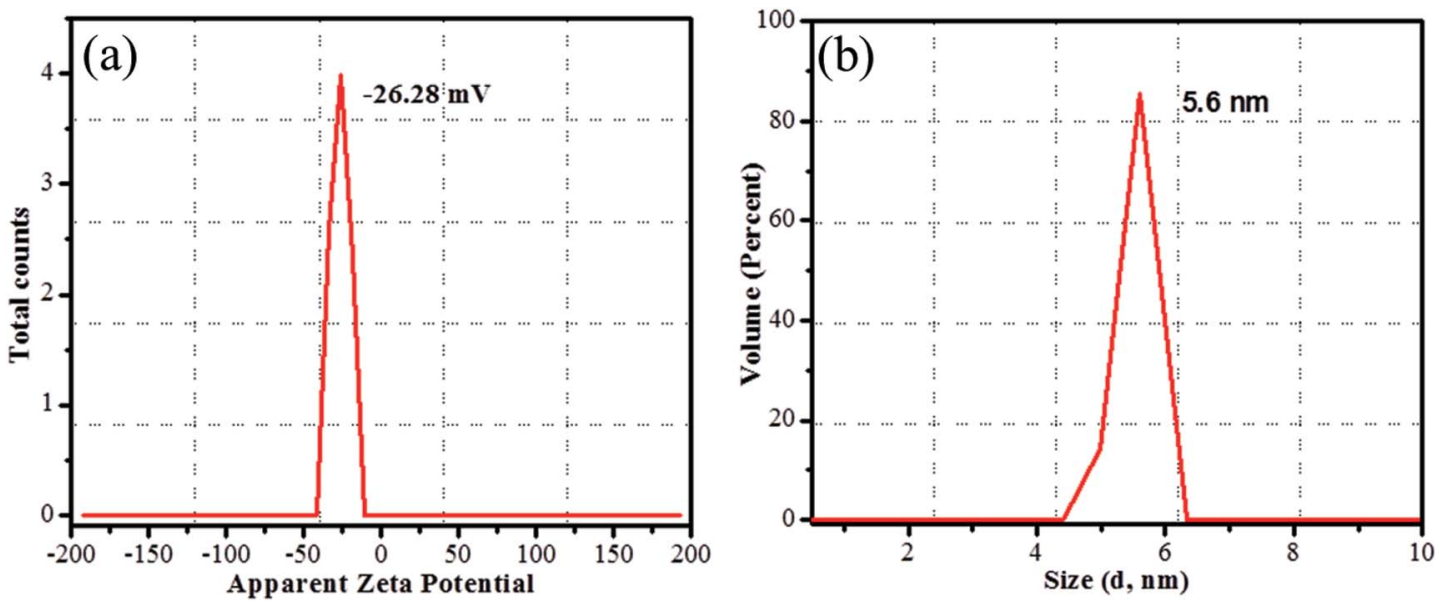

Fig. 1 Zeta potential (a) charge of GSH-CDs, (b) hydrodynamic diameter of GSH-CDs.

(lysine, histidine, arginine, valine, methionine, isoleucine, leucine, and phenylalanine) it was used as a source of carbon. ${ }^{51}$ The glutathione precursor was selectively used to passivate the CDs because of its multiple functional groups $(-\mathrm{COOH},-\mathrm{CO}$, and $-\mathrm{NH}_{2}$ ), which provide an abundance of oxygen- and nitrogen-rich species at their surface. The surfaces of the GSHCDs were negatively charged due to the passivation of carboxylic, carbonyl and hydroxyl groups. These functional groups act as a sensing probe and have a high ability to chelate with $\mathrm{As}^{3+}$ / $\mathrm{ClO}^{-}$ions in drinking water samples. The preparation method holds novelty in the surface modification of CDs via a singlestep green synthesis procedure and in the selective analysis of dual ions. The zeta potential measurement of GSH-CDs the resulted in a negatively charged surface $(-26.28 \mathrm{mV})$ due to the functionalization of the carboxylic group over the surface, as shown in Fig. 1a. The sizes of the GSH-CDs were measured to be $5.6 \mathrm{~nm}$, as shown in Fig. 1b, which is similar to the histogram chart in Fig. 2d.

The structural morphology of the GSH-CDs particles was confirmed by high-resolution transmission electron microscopy
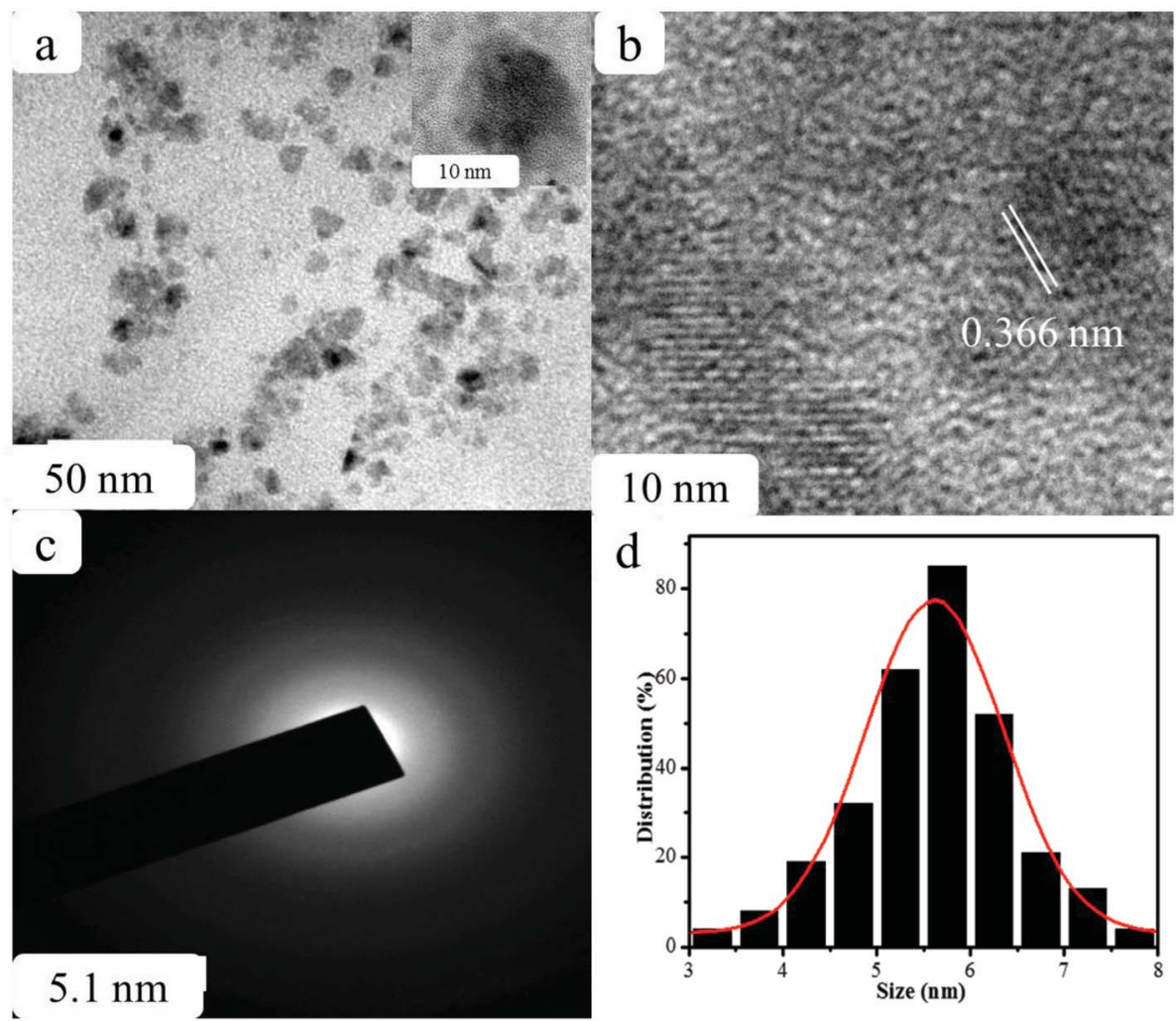

Fig. 2 (a) TEM, (b) HR-TEM images, (c) SAED pattern, and (d) particle size distribution histogram of GSH-CDs. 


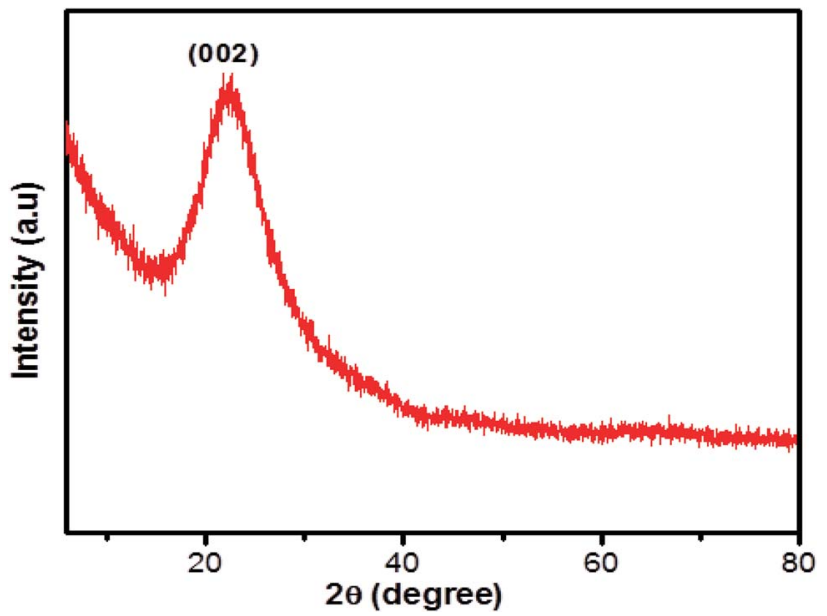

Fig. 3 XRD pattern of GSH-CDs.

(HR-TEM) analysis, as shown in Fig. 2. The TEM images of GSHCDs found they were dispersed and the particle sizes were in the range of 3.0 to $8.0 \mathrm{~nm}$ in histogram chart with an average size of $5.6 \mathrm{~nm}$. The phase purity of the prepared GSH-CDs probe was determined by an X-ray (XRD) diffraction technique. Fig. 3 depicts the XRD profile of the blue-emitting CDs, where a broad peak centered at $22.3^{\circ}$ can be recognized as the (002) diffraction pattern, which also endorsed the existence of oxygen-containing functional groups. ${ }^{52}$ The SAED pattern in Fig. $2 c$ indicates the poor crystalline nature. The HR-TEM image of GSH-CDs (Fig. 2b) shows a fringe spacing of $0.366 \mathrm{~nm}$, which agreed well with the spacing of the (002) diffraction pattern.

The prepared quantum dots were further confirmed by FT-IR spectroscopy. The functional groups of GSH-CDs were successfully passivated at the surface of the sensor. As shown in Fig. 4a, the broad absorption band at $3398 \mathrm{~cm}^{-1}$ was assigned to the stretching vibration of an $\mathrm{O}-\mathrm{H}$ group and the absorption

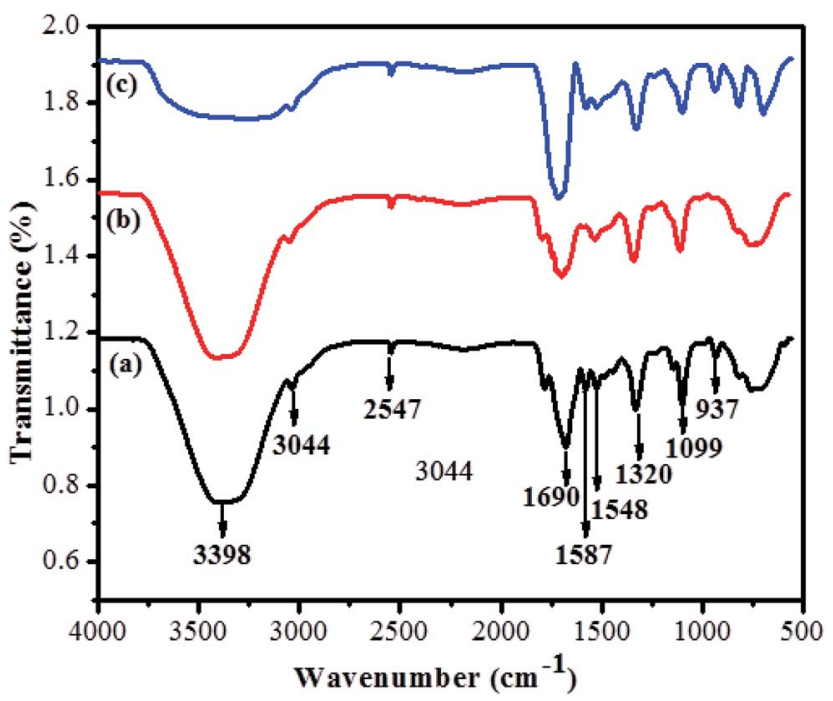

Fig. 4 (a) FTIR patterns of GSH-CDs, (b) with $\mathrm{As}^{3+}$ and (c) with $\mathrm{ClO}^{-}$ ions. band at $3044 \mathrm{~cm}^{-1}$ was attributed to stretching vibrations of a $\mathrm{C}-\mathrm{H}$ group. The characteristic absorption bands at 1690 and $937 \mathrm{~cm}^{-1}$ were attributed to stretching and bending vibrations of the $\mathrm{C}-\mathrm{O}$ and $\mathrm{O}-\mathrm{H}$ groups of carboxylic acid. Furthermore, the absorption bands at 1587 and $1548 \mathrm{~cm}^{-1}$ were assigned to stretching and bending vibrations of $\mathrm{C}=\mathrm{O}$ and $\mathrm{NH}_{2}$, respectively. The peaks about 1320 and $2547 \mathrm{~cm}^{-1}$ were attributed to stretching of $\mathrm{C}-\mathrm{O}$ groups and band vibrations of $\mathrm{S}-\mathrm{H}$ groups in the GSH-CDs. In Fig. 4b, the asymmetric and symmetric stretching vibration intensities at 1690 and $937 \mathrm{~cm}^{-1}$ were decreased due to the chelation of $\mathrm{COO}^{-}$ions with $\mathrm{As}^{3+}$ ions. In Fig. 4c, the absorption bands intensities at $3398 \mathrm{~cm}^{-1}$ and $1032 \mathrm{~cm}^{-1}$ were decreased due to reduction of the $\mathrm{O}-\mathrm{H}$ stretching peaks. New peaks appear in a range of 1000 to $400 \mathrm{~cm}^{-1}$ and represent the absorption bands due to the coordination of $\mathrm{ClO}^{-}$ions.

The fluorescence decay of GSH-CDs with and without $\mathrm{As}^{3+} /$ $\mathrm{ClO}^{-}$ions were measured, as interpreted in Fig. 5a. The quenching mechanism of GSH-CDs were analyzed with the desired concentration of $\mathrm{As}^{3+} / \mathrm{ClO}^{-}$ions by measuring the correlated charge transfer and excited recombination process in the presence and absence of $\mathrm{As}^{3+} / \mathrm{ClO}^{-}$ions. The lifetimes of the bare GSH-CDs were found to be very short, as represented by the blue line in the figure, which implies a fast excited recombination process with an average lifetime of 2.752 ns. Furthermore, the decay processes examined with the addition of $\mathrm{As}^{3+}$ ions (black line) and $\mathrm{ClO}^{-}$(red line) indicated an increase in the decay component, which holds with an average lifetime of $3.0653 \mathrm{~ns}$ and $2.894 \mathrm{~ns}$. These results demonstrated that the quenching of the fluorescence intensity upon the addition of $\mathrm{As}^{3+} / \mathrm{ClO}^{-}$was a static quenching process.

The emission spectra of the surface-passivated GSH-CDs were observed at different excitation wavelengths in the range of 370 to $490 \mathrm{~nm}$, as shown in Fig. 5b. The obtained spectra signified a red-shift with a decrease in the fluorescence intensity (446-536 nm) by increasing the excitation from 370 to $490 \mathrm{~nm}$, due to the surface energy traps of CDs by the passivation of glutathione. The relative fluorescence quantum yield of oxygenrich GSH-CDs were measured to be $12.7 \%$. The specificity in quenching of the emission intensity could be used as a signaling unit to identify the presence of toxic ions.

The surface-passivated oxygen-rich CDs were excellently water soluble. UV-vis absorption analysis showed strong absorption bands centered at $278 \mathrm{~nm}$ and $402 \mathrm{~nm}$, which were assigned as $\mathrm{n}-\pi^{*}$ transition of $\mathrm{C}=\mathrm{O}$ bonds and $\pi-\pi^{*}$ transition of $\mathrm{C}=\mathrm{C}$ groups, as shown in Fig. 5c. The emission intensity of the as-prepared GSH-CDs was monitored with a fluorescence spectrophotometer. The blue emission of oxygen-rich CDs revealed a strong emission peak centered at $446 \mathrm{~nm}$ with an excitation of $355 \mathrm{~nm}$, as shown in Fig. 5d. The obtained yellow suspension appeared bright blue under UVvisible light $(365 \mathrm{~nm})$, as shown in the inset image of Fig. 5d. The fluorescence characterization results showed it was a positive approach to use GSH-CDs as a sensing system to analyze toxic ions. 

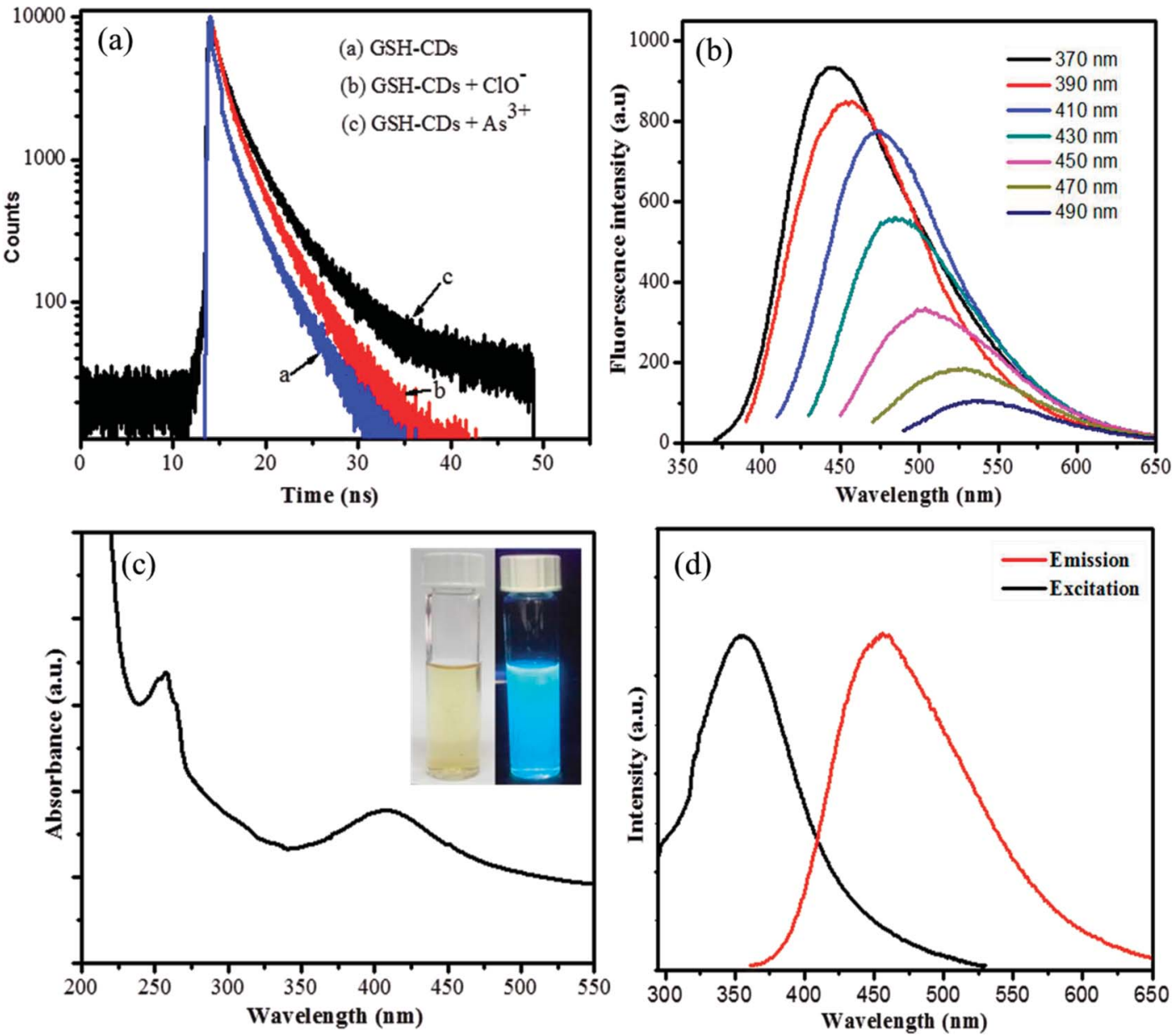

Fig. 5 (a) Fluorescence decay curves of GSH-CDs (blue colored curve (a)), GSH-CDs with ClO- (red colored curve (b)), and GSH-CDs with As ${ }^{3+}$ (black colored curve (c)). (b) Excitation-dependent fluorescence emission of GSH-CDs with excitation from 370 to $490 \mathrm{~nm}$. (c) UV-vis absorption spectra of GSH-CDs. The inset image is an aqueous dispersion of GSH-CDs in day light and UV light, respectively. (d) Fluorescence excitation and emission response of the GSH-CDs.

\subsection{Influence of $\mathbf{p H}$}

The fluorescence response of GSH-CDs was investigated under a wide range of $\mathrm{pH}(2-11)$ in an aquatic medium, as depicted in Fig. 6a. The functionalized hydroxyl and organic acid groups on CDs were protonated in an acidic medium until the $\mathrm{pH}$ was $<4$, resulting in a low quenching efficiency. As the $\mathrm{pH}$ increased from 4 to 8 , the fluorescence intensity significantly decreased due to the high quenching efficiency and maximum quenching was observed in a neutral medium $(\mathrm{pH}=7)$. This is due to deprotonation of the functionalized groups, which increases the covalent bond strength between the GSH-CDs and $\mathrm{As}^{3+}$ ions. As the $\mathrm{pH}$ further increases $(\mathrm{pH}>8)$, the $\mathrm{As}^{3+}$ ions tend to form complexes about $\mathrm{OH}^{-}$ions in the aquatic medium, which results in a poor interaction with the CDs. ${ }^{53}$ The maximum response in neutral medium could be attributed to a better interaction between the functionalized CDs and the metal ions. Hence the sensitive and selective detection of $\mathrm{As}^{3+}$ ions was feasible in the drinking water sample.

The fluorescence intensity of the GSH-CDs was explored for their use as a suitable sensing probe for the detection of $\mathrm{ClO}^{-}$ ions in aqueous solution. The sensitivity of the sensing probe was investigated in a wide range of $\mathrm{pH}$ values from 2 to 12 to identify the better response of GSH-CDs, as shown in Fig. 6b. The results revealed that the $\mathrm{pH}$ of the medium is an important factor to analyze the correlation between the sensitivity of the probe and the $\mathrm{ClO}^{-}$ions. The $\mathrm{pH}$ plays a critical role in the sensing of $\mathrm{ClO}^{-}$ions, whereby the hydroxyl and organic acid groups on the surface of GSH-CDs were protonated in the acid medium and deprotonated in a strong basic medium. The fluorescence intensity varied at different $\mathrm{pH}$ values, depending on the oxidative interaction of $\mathrm{ClO}^{-}$ions with the sensing probe. In acidic conditions, the sensitivity of the probe was very poor due to the low interaction with $\mathrm{ClO}^{-}$ions as they were instead converted into $\mathrm{HClO}$. Whereas in alkaline medium at $\mathrm{pH}>8$, the sensitivity was poor due to the prolonged contact time of $\mathrm{ClO}^{-}$with the sensing probe, leading to its poor efficiency at interacting with the surface functional groups. ${ }^{54}$ Furthermore, NaClO may be hydrolyzed to $\mathrm{HClO}$ and $\mathrm{ClO}^{-}$in an aqueous solution and the reaction remains incomplete at $\mathrm{pH}$ 6.5 to 8.5. Thus the active $\mathrm{HClO}$ and $\mathrm{ClO}^{-}$ions are found to exist 

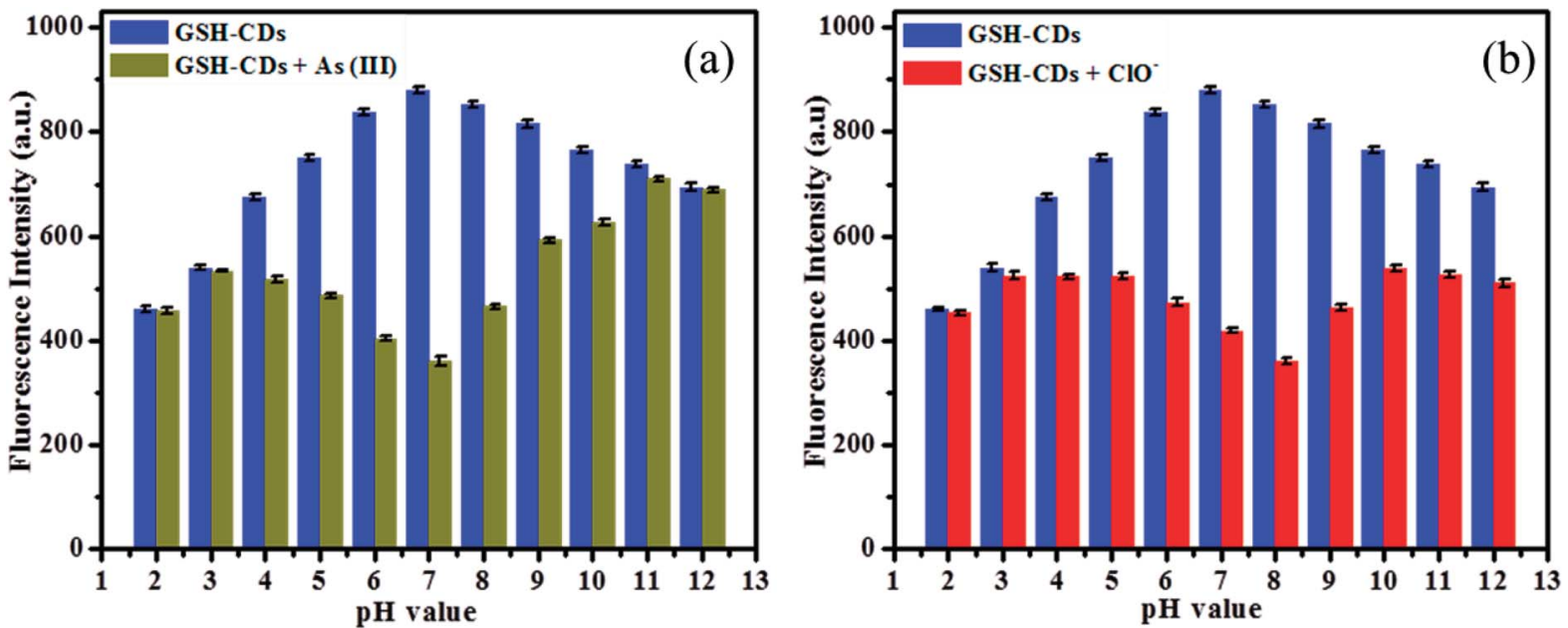

Fig. 6 (a) Fluorescence intensity of GSH-CDs $(10 \mu \mathrm{L})$ at various $\mathrm{pH}(2-12)$ with and without $\mathrm{As}^{3+}(25 \mathrm{nM})$, and (b) Fluorescence intensity of GSHCDs at various $\mathrm{pH}(2-12)$ with and without $\mathrm{ClO}^{-}(100 \mu \mathrm{M})$.

in neutral and weakly alkaline media. The fluorescence emission spectra were analyzed for the detection of $\mathrm{ClO}^{-}$ions and the sensor showed a better response at $\mathrm{pH}$ values between 6 and 9. The maximum quenching response was observed at $\mathrm{pH} 8$ with the peak centered at $456 \mathrm{~nm}$ and excited at $355 \mathrm{~nm}$.

\subsection{Sensitivity of GSH-CDs toward $\mathrm{As}^{3+} / \mathrm{ClO}^{-}$ions}

The sensitivity study of the emission spectra of the GSH-CDs provided a useful correlation between the quenched emission intensity of the sensing system and the concentration of $\mathrm{As}^{3+} /$ $\mathrm{ClO}^{-}$ions. The glutathione-passivated $\mathrm{CDs}$ showed a high affinity for the effective detection of $\mathrm{As}^{3+}$ ions under optimum conditions. As shown in Fig. 7a, upon increasing the concentration of $\mathrm{As}^{3+}(0-30 \mathrm{nM})$ ions, the emission intensity of GSHCDs was strongly quenched, with an emission peak centered at $456 \mathrm{~nm}$ as excited at $355 \mathrm{~nm} .{ }^{64,65}$ The quenching efficiency of the sensor revealed the sensitivity of the surface functional groups (carboxylic groups) toward $\mathrm{As}^{3+}$ ions. The quenching efficiency was directly proportional to the concentration of $\mathrm{As}^{3+}$ ions and its linear correlation was plotted to identify the working range. The analyzed data was applied in the SternVolmer equation to confirm whether the sensing mechanism was dynamic or static: $F_{0} / F=1+K_{\mathrm{sv}} C$, where, $K_{\mathrm{sv}}$ is a SternVolmer constant, $C$ is the concentration of metal ions, and $F$ and $F_{0}$ represent the fluorescence intensity of GSH-CDs in the presence and absence of $\mathrm{As}^{3+}$ ions. The plot (Fig. 7b) displays a linear fit $\left(R^{2}=0.9987\right)$ when increasing the $\mathrm{As}^{3+}$ concentration (2-12 nM) and achieved a lower detection limit of $2.3 \mathrm{nM}$ as calculated by the $3 s / k$ method (where $s$ is the standard deviation of the blank measurement (0.00483) and $k$ is the slope (6.19878), so the calculated LOD is $=(3 \times 0.00483) /(6.19878)=2.3375){ }^{66}$ The achieved detection limit is compared with the previously reported materials for $\mathrm{As}^{3+}$ sensing in Table 1, and the results clearly suggest that the GSH-CDs have remarkable sensitivity
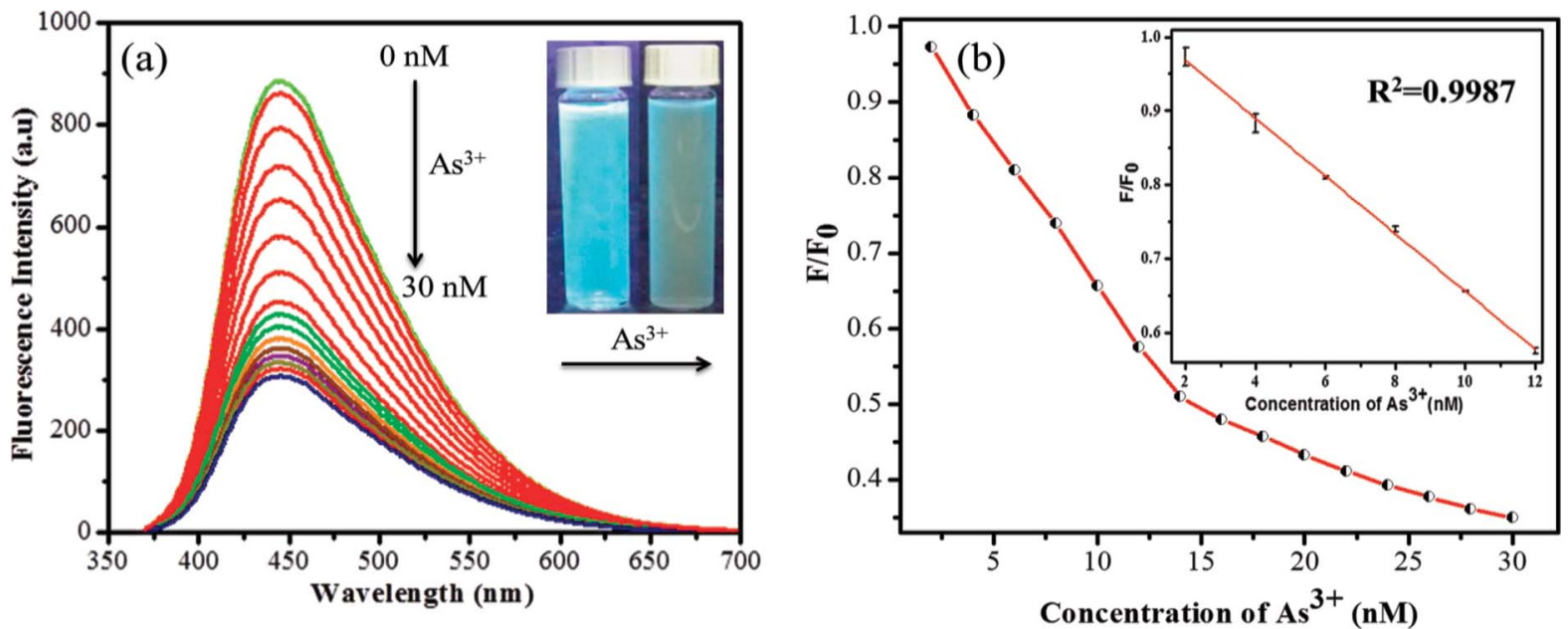

Fig. 7 (a) Fluorescence emission response of $10 \mu \mathrm{LGSH}-\mathrm{CDs}$, to various molar equivalents of $\mathrm{As}^{3+}$ ions $(0$ to $30 \mathrm{nM})$ in $1000 \mu \mathrm{L}$ of tris- $\mathrm{HAc}$ buffer (10 mM, pH 7.4). (b) Stern-Volmer plot with an inset plot shows the linearity for $\mathrm{As}^{3+}$ ions (2 to $12 \mathrm{nM}$ ). 

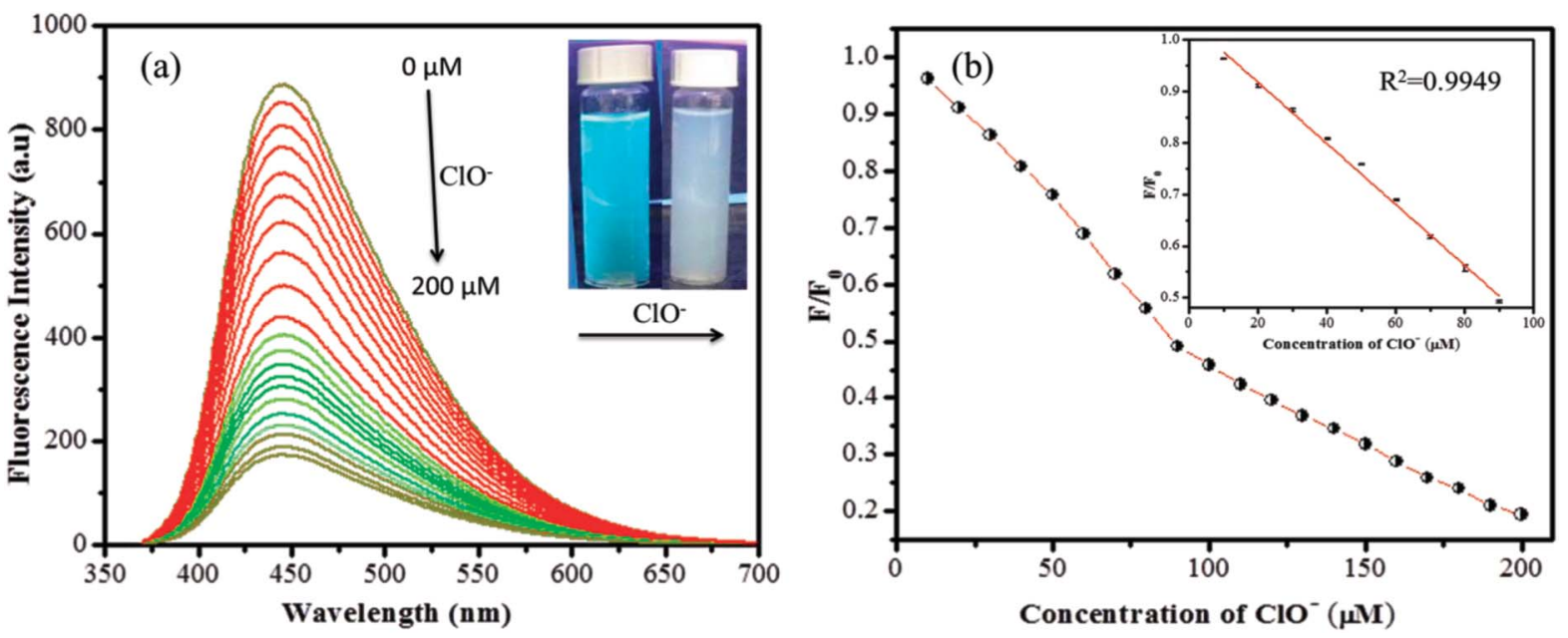

Fig. 8 (a) Fluorescence emission response of $10 \mu \mathrm{L} \mathrm{GSH-CDs,} \mathrm{to} \mathrm{various} \mathrm{molar} \mathrm{equivalents} \mathrm{of} \mathrm{ClO}^{-}$ions (0 to $\left.200 \mu \mathrm{M}\right)$ in $1000 \mu \mathrm{L}$ of tris- $\mathrm{HAc}$ buffer (10 mM, pH 7.4). (b) Stern-Volmer plot shows the linearity for $\mathrm{ClO}^{-}$ions (10 to $\left.90 \mu \mathrm{M}\right)$.

and indicate the possibility for the probe to be used for $\mathrm{As}^{3+}$ sensing in drinking water.

Similarly the fluorescence quenching of GSH-CDs in the presence of $\mathrm{ClO}^{-}$ions was analyzed in the range of $0-200 \mu \mathrm{M}$, as shown in Fig. 8. The sensitivity of the sensing probe revealed an excellent linearity in the range of $10-90 \mu \mathrm{M}$ with a correlation coefficient of $R^{2}=0.9949$, as shown in the inset of Fig. 8b. Similar experimental conditions were followed to calculate the detection limit of $\mathrm{ClO}^{-}$ions and it was found to be $0.016 \mu \mathrm{M}$. The sensing probe of GSH-CDs showed a strong affinity with $\mathrm{ClO}^{-}$ions in the drinking water. The obtained results are compared with the reported literature in Table 2 . The sensitivity analysis suggested that the GSH-CDs can be used as an excellent sensor for $\mathrm{As}^{3+}$ / $\mathrm{ClO}^{-}$ions with improved performance and simplicity.

\subsection{Selectivity and coexisting ions effect on GSH-CDs}

To explore the selectivity of the established fluorescent sensor (GSH-CDs), it was important to perform the analysis under optimized conditions. The fluorescence quenching intensity was studied for $\mathrm{As}^{3+}(25 \mathrm{nM})$ and $\mathrm{ClO}^{-}(100 \mu \mathrm{M})$ ions in the presence of other cations $(25 \mathrm{nM})$ and anions $(100 \mu \mathrm{M})\left(\mathrm{Ag}^{+}, \mathrm{K}^{+}\right.$, $\mathrm{Ca}^{2+}, \mathrm{Cu}^{2+}, \mathrm{Ni}^{2+}, \mathrm{Ba}^{2+}, \mathrm{Pb}^{2+}, \mathrm{Hg}^{2+}, \mathrm{Cd}^{2+}, \mathrm{Co}^{2+}, \mathrm{Fe}^{2+}, \mathrm{Fe}^{3+}, \mathrm{ClO}^{-}$, $\mathrm{Br}^{-}, \mathrm{I}^{-}, \mathrm{SCN}^{-}, \mathrm{NO}_{2}{ }^{-}, \mathrm{PO}_{4}{ }^{3-}, \mathrm{H}_{2} \mathrm{PO}_{4}{ }^{-}$, and $\mathrm{SO}_{4}{ }^{2-}, \mathrm{ONOO}^{-}, \cdot \mathrm{OH}$, $\left.\mathrm{O}_{2}^{-\cdot}\right)$ in a tris-HAc buffer solution $(10 \mathrm{mM}, \mathrm{pH} 7.4)$ and $10 \mu \mathrm{L}$ GSH-CDs solution, as shown in Fig. 9. The fluorescence intensity of the GSH-CDs in the absence and presence of the other metal ions was observed and the change in emission intensity was denoted by a red and green bar. ${ }^{67}$ The drastic quenching efficiency was observed in the presence of $\mathrm{As}^{3+}$ or $\mathrm{ClO}^{-}$ions as represented by the green bar. In contrast, no tremendous decrease in emission intensity was observed upon the addition of other metal ions into the GSH-CDs dispersion, as represented by the red bar. These results indicated that the GSH-CDs were predominantly selective toward $\mathrm{As}^{3+}$ and $\mathrm{ClO}^{-}$ions.

To examine the selectivity of GSH-CDs, the emission responses in the presence of other competitive metal ions were investigated. Under optimum conditions, $\mathrm{As}^{3+}(25 \mathrm{nM})$ or $\mathrm{ClO}^{-}$ $(100 \mu \mathrm{M})$ solution were added to a GSH-CDs dispersion of competitive ions. The interference with other ions is depicted in the emission spectra, as shown in Fig. 10a. The emission intensity for $\mathrm{As}^{3+}$ or $\mathrm{ClO}^{-}$ions was found to be quenched as they form a complex with the sensing probe. Similarly the quenching efficiency was investigated at a higher concentration of other competitive cations $(30 \mathrm{nM})$ and anions $(150 \mu \mathrm{M})$, as shown in Fig. 10b. The influence of other competitive ions had an insignificant effect on the emission band, even at higher concentration. This investigation implied that the GSH-CDs as a fluorometric sensor were highly selective and specific to $\mathrm{As}^{3+}$ or $\mathrm{ClO}^{-}$ions over the other metal ions, indicating the possibility of the sensor to be applied in the sensing $\mathrm{As}^{3+}$ or $\mathrm{ClO}^{-}$ions in drinking water.

The interference study reveals that the proposed sensor was more selective toward $\mathrm{As}^{3+}$ or $\mathrm{ClO}^{-}$ions with the coexistence of other metal ions. Yet, it is to be noted that $\mathrm{ClO}^{-}$ions showed a strong interference with GSH-CDs to quench the emission intensity more in the detection of $\mathrm{As}^{3+}$ ions. In the attempt to sense $\mathrm{ClO}^{-}$ions, the quenching efficiency of the sensor was significantly altered by interference with $\mathrm{As}^{3+}$ ions. This was attributes to the mutual interference of $\mathrm{As}^{3+}$ and $\mathrm{ClO}^{-}$ions with the sensing probe. Hence, we focused on the recovery study to prove the selectivity of $\mathrm{As}^{3+}$ and $\mathrm{ClO}^{-}$ions. L-Cysteine and sodium borohydride were used as chelators to capture the $\mathrm{As}^{3+}$ and $\mathrm{ClO}^{-}$ions as metal chelates. The interference with $\mathrm{As}^{3+}$ and $\mathrm{ClO}^{-}$ions toward the GSH-CDs probes were insignificant in the presence of L-cysteine and sodium borohydride, as shown in Fig. 11. The selectivity and specificity for $\mathrm{As}^{3+}$ or $\mathrm{ClO}^{-}$ions were due to the stronger affinity with carboxylic and hydroxyl functional groups on the surface of CDs than the other ions.

\subsection{Sensing mechanism for the detection of $\mathrm{As}^{3+} / \mathrm{ClO}^{-}$ions}

The fluorescence signal of the GSH-CDs was selectively quenched toward $\mathrm{As}^{3+} / \mathrm{ClO}^{-}$ions, possibly due to the complex 


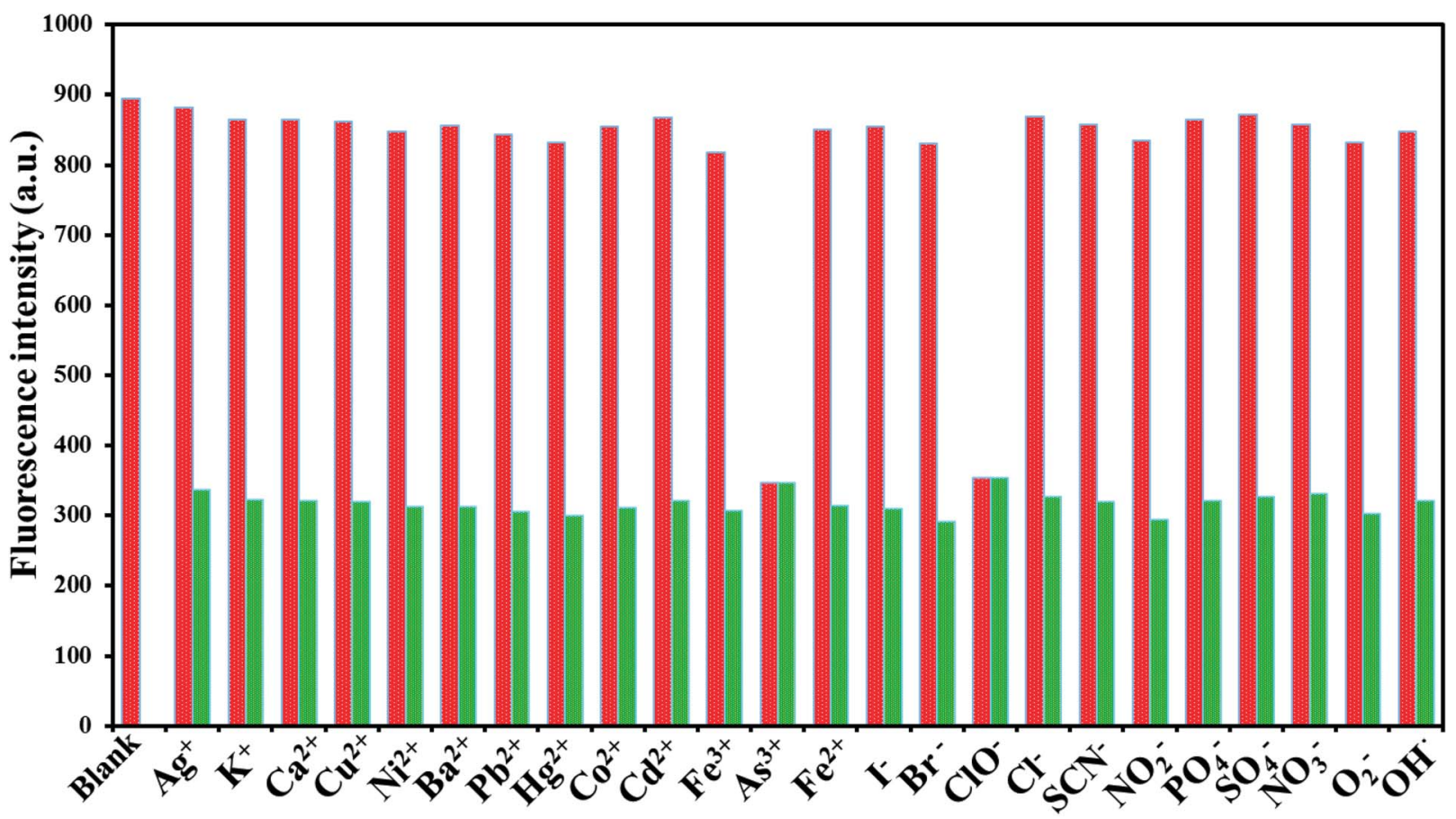

Fig. 9 Fluorescence response of $10 \mu \mathrm{L} \mathrm{GSH-CDs,} \mathrm{to} \mathrm{various} \mathrm{molar} \mathrm{equivalents} \mathrm{of} \mathrm{cations} \mathrm{(25} \mathrm{nM)} \mathrm{and} \mathrm{anions} \mathrm{(100} \mu \mathrm{M})$ in $1000 \mu \mathrm{L}$ of tris-HAc buffer (10 mM, pH 7.4).

formation of As-O on the surface of the CDs, as represented in Scheme 1. The surface passivation with glutathione enriches the surface with functional groups containing $\mathrm{O}$ and $\mathrm{N}$ species, which shows a good ability of chelation with ions. ${ }^{68}$ The GSHCDs showed a high selectivity and sensitivity for $\mathrm{As}^{3+}$ ions based on quenched fluorescence via a turn-off mechanism, which could be recognized by an inner filter effect, the available functional groups, ion binding interactions, and electrontransfer process. ${ }^{68}$ In the selectivity study, fluorescence spectra were recorded for various metal ions and it was noted that $\mathrm{As}^{3+}$ ions had a strong affinity to quenching the fluorescence intensity of GSH-CDs with emission peaks at $456 \mathrm{~nm}$ excited at
$355 \mathrm{~nm}$. The result showed that $\mathrm{As}^{3+}$ ion were more specific toward the organic acid groups of the sensing probe than the other metal ions in this sensing system. Thus the fluorescence quenching may be attributed to the selective interaction between excited GSH-CDs and $\mathrm{As}^{3+}$ ions, which could be recognized as an energy or electron-transfer process. The FT-IR spectra confirmed the surface functionalization of organic acid. The aqueous solution of GSH-CDs was strongly quenched by $\mathrm{As}^{3+}$ ions in a non-radiative electron-transfer process.

We explored the feasibility of performing the sensitive detection of $\mathrm{ClO}^{-}$ions by GSH-CDs. The sensor exhibited a strong emission peak at $465 \mathrm{~nm}\left(\lambda_{\mathrm{ex}}=355 \mathrm{~nm}\right)$ upon titration,
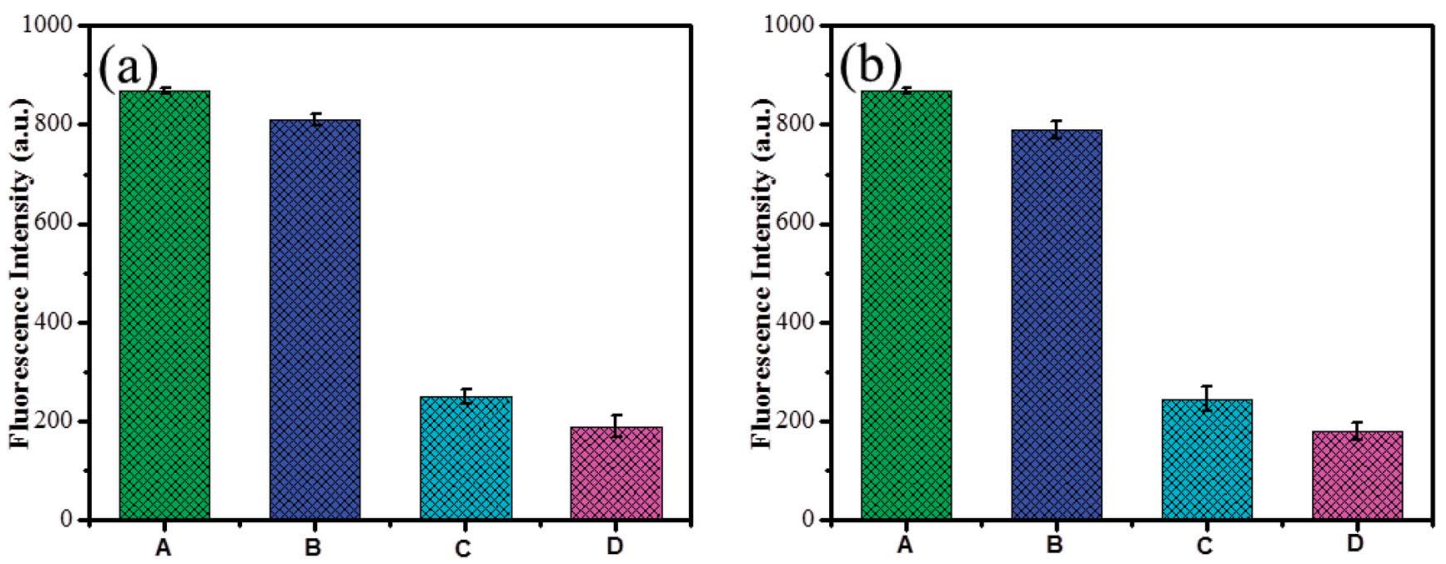

Fig. 10 (a) Fluorescence response of (A) $10 \mu \mathrm{LGH}-\mathrm{CDs}$, (B) other ionic mixture $\mathrm{Ag}^{+}, \mathrm{K}^{+}, \mathrm{Ca}^{2+}, \mathrm{Cu}^{2+}, \mathrm{Ni}^{2+}, \mathrm{Ba}^{2+}, \mathrm{Pb}^{2+}, \mathrm{Hg}^{2+}, \mathrm{Cd}^{2+}, \mathrm{Co}^{2+}, \mathrm{Fe}^{2+}$,

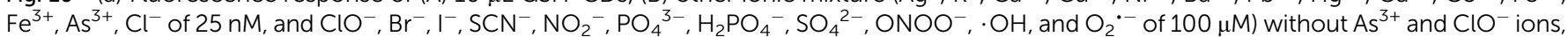
(C) other ionic mixtures with $25 \mathrm{nM}$ of $\mathrm{As}^{3+}$ and without $\mathrm{ClO}^{-}$ions and (D) other ionic mixtures with $100 \mu \mathrm{M}$ of $\mathrm{ClO}^{-}$ions of $100 \mu \mathrm{M}$ and without $\mathrm{As}^{3+}$. (b) Is a similar analysis of (a), followed with a higher concentration of other competitive cations (30 nM), and anions (150 $\left.\mu \mathrm{M}\right)$. 

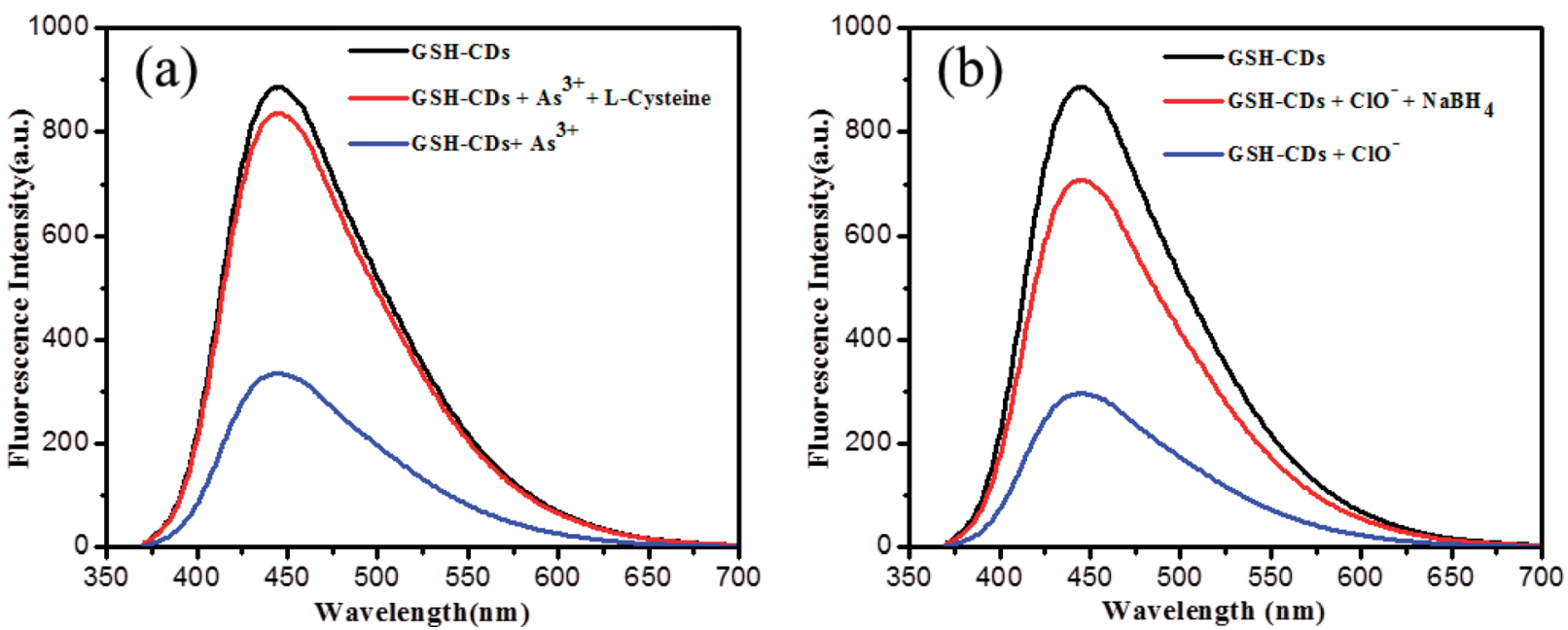

Fig. 11 (a) Fluorescence response $10 \mu \mathrm{L}$ of GSH-CDs for $\mathrm{As}^{3+}$ ions ( $25 \mathrm{nM}$ ) and recovery of L-cysteine. (b) Fluorescence response of GSH-CDs for $\mathrm{ClO}^{-}$ions $(100 \mu \mathrm{M})$ and the recovery of $\mathrm{NaBH}_{4}$.

whereby the quenching of the fluorescence intensity increased with the increase in the concentration of $\mathrm{ClO}^{-}$ions. The FT-IR spectra confirmed that the hydroxyl functional group on the surface of the GSH-CDs was a reductive group and that it readily interacts with oxidizing substances to quench the fluorescence intensity. The oxidation of hydroxyl groups on the surface brought about a change by $\mathrm{ClO}^{-}$ion with the excellent quenching efficiency of GSH-CDs. The fluorescence quenching mechanism of GSH-CDs with $\mathrm{ClO}^{-}$is proposed in Scheme 1. In the aqueous solution, $\mathrm{NaClO}$ hydrolyzes to form $\mathrm{HClO}$ and $\mathrm{ClO}^{-}$ and this reaction remains incomplete in a $\mathrm{pH}$ range of 6.5 to 8.5 and hence both species are found to exist in neutral and weakly alkaline media. An interactive sensing mechanism was thus proposed based on the previously reported literature, ${ }^{69,70}$ whereby:

$$
\mathrm{NaOCl}+\mathrm{H}_{2} \mathrm{O} \rightarrow \mathrm{Na}^{+}+\mathrm{HClO}+\mathrm{OH}^{-}
$$

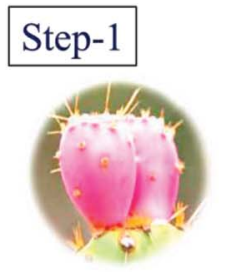

Prickly Pear Cactus

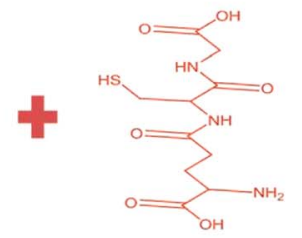

Glutathione (GSH)

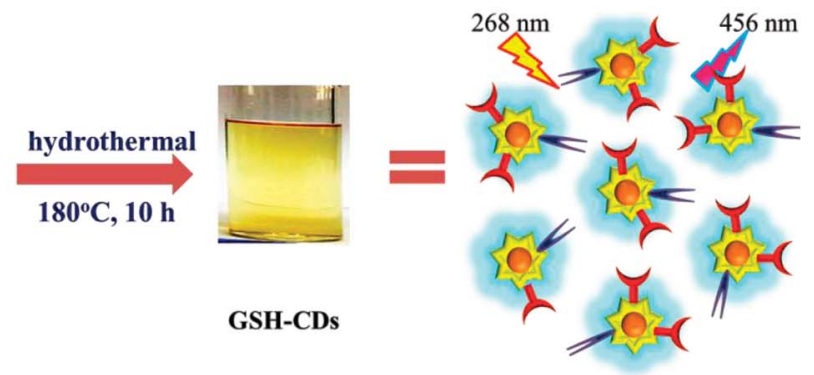

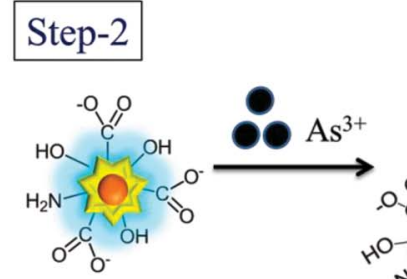

GSH-CQDs

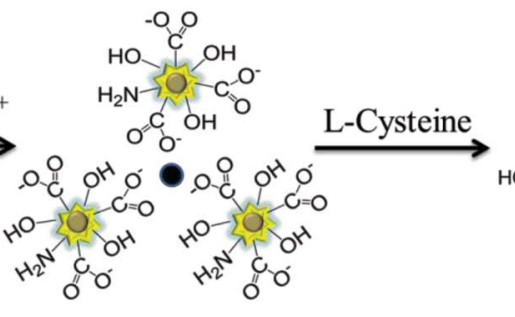

HO C, $^{\mathrm{O}, \mathrm{OH}}$

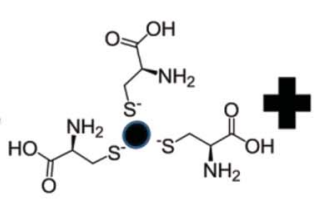

$\mathrm{H}_{2}$

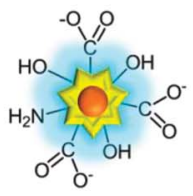

GSH-CDs

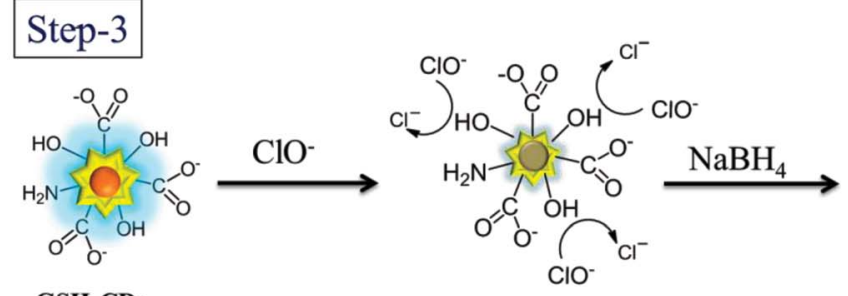

GSH-CDs
$\mathrm{HClO}^{-}$

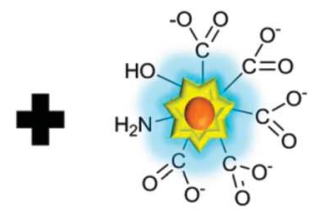

GSH-CDs

Scheme 1 Schematic illustration of the design and working principle. 

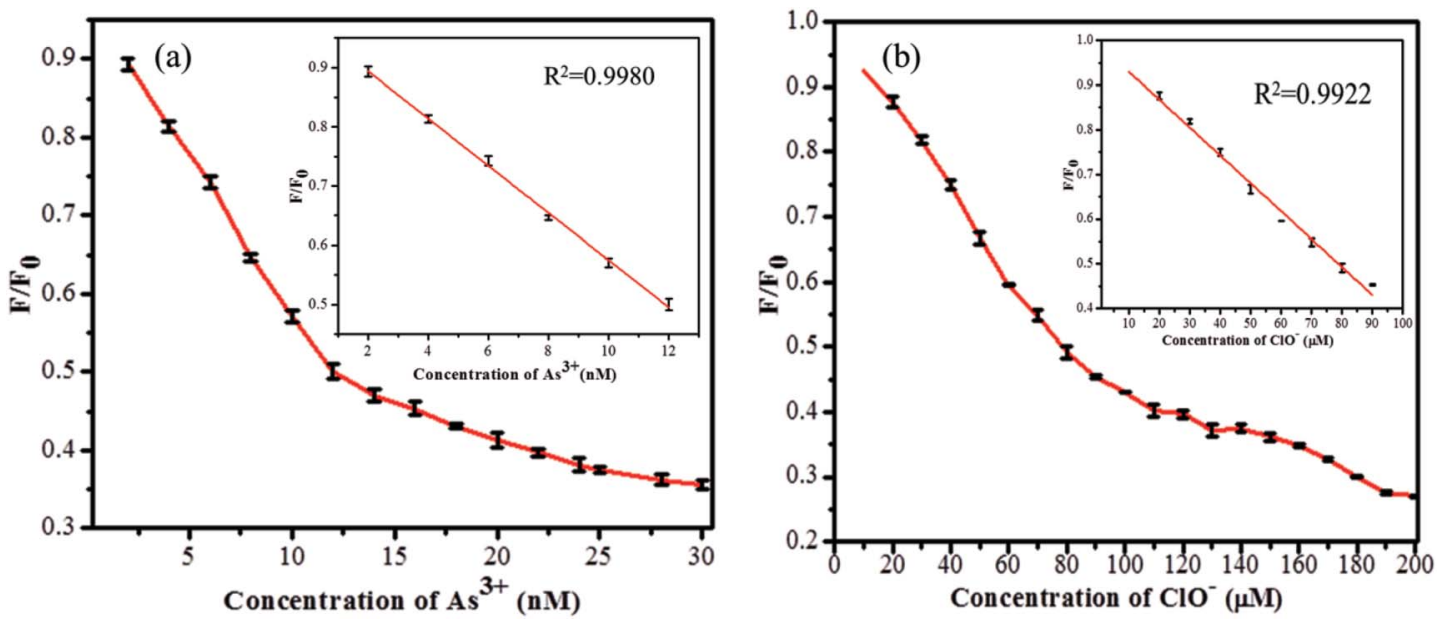

Fig. 12 (a) Fluorescence response of GSH-CDs for $\mathrm{As}^{3+}$ ions $(0-30 \mathrm{nM})$ in tap water, (b) for $\mathrm{ClO}^{-}$ions $(0-200 \mu \mathrm{M})$ in tap water. The triplicated data were fitted in the linearity equation of $F_{0} / F$ for tap water sample analysis, shown as in insert image.

$$
\mathrm{HClO} \leftrightarrow \mathrm{H}^{+}+\mathrm{ClO}^{-}
$$

The surface interaction between GSH-CDs and $\mathrm{ClO}^{-}$are

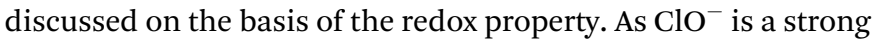
oxidant, it modifies the electron-hole state of oxidized $\mathrm{GSH}$ CDs, whereby:

$$
\begin{gathered}
\mathrm{GSH}-\mathrm{CDs}+\mathrm{ClO}^{-}+\mathrm{H}_{2} \mathrm{O} \rightarrow \mathrm{GSH}_{-\mathrm{CDs}}{ }^{+}+\cdot \mathrm{Cl}+2 \mathrm{OH}^{-} \\
\mathrm{GSH}-\mathrm{CDs}+\cdot \mathrm{Cl} \rightarrow \mathrm{GSH}-\mathrm{CDs}^{\cdot+}+\mathrm{Cl}^{-}
\end{gathered}
$$

The effective quenching of GSH-CDs was caused by the change in the surface state by the strong oxidizer $\mathrm{ClO}^{-}$ions, which oxidize the surface hydroxyl functional group into $-\mathrm{COO}^{-}$. The suggested mechanism below explains the possible quenching ability of $\mathrm{CDs}$ with $\mathrm{ClO}^{-}$ions:

$$
\text { GSH-CDs-C-OH }+\mathrm{ClO}^{-} \rightarrow \mathrm{GSH}-\mathrm{CDs}-\mathrm{COO}^{-}+\mathrm{Cl}^{-}+\mathrm{HClO}
$$

The interactive mechanism is confirms by the change in surface state via quenching the fluorescence intensity of GSHCDs. The FT-IR spectra evidenced the surface modification of the $\mathrm{O}-\mathrm{H}$ group. Upon the addition of $\mathrm{ClO}^{-}$ions to the sensing system, the intensity of the $\mathrm{O}-\mathrm{H}$ stretching peak decreases and a new peak appears at $680 \mathrm{~cm}^{-1}$, ascribed to the absorption band of $\mathrm{ClO}^{-}$ions. The organic acid and hydroxyl groups on the surface of GSH-CDs can specifically detect $\mathrm{As}^{3+} / \mathrm{ClO}^{-}$ions.

\subsection{Detection of $\mathrm{As}^{3+}$ and $\mathrm{ClO}^{-}$ions in real samples}

To further assess the applicability of the GSH-CDs in practical applications for the detection of $\mathrm{As}^{3+} / \mathrm{ClO}^{-}$ions, collected real water samples were filtered using a $0.22 \mu \mathrm{m}$ membrane, and then centrifuged for $10 \mathrm{~min}$ at $12000 \mathrm{rpm}$. The $\mathrm{pH}$ value was altered with tris-HAc buffer solution $(\mathrm{pH}$ 7.4) for the sensitive analysis. The optimized tap water sample was spiked with various concentrations of $\mathrm{As}^{3+}$ and $\mathrm{ClO}^{-}$ions in an increasing range of $0-30 \mathrm{nM}$ and $0-200 \mu \mathrm{M}$, respectively. The sensing performance was triplicated and the resulting data were fitted using the linearity equation of $F / F_{0}$ (Fig. 12). The plot displayed a good linear fits of $R^{2}=0.9965$ and 0.9922 for $\mathrm{As}^{3+}$ and $\mathrm{ClO}^{-}$, in a range of 2-12 $\mathrm{nM}$ and $10-90 \mu \mathrm{M}$, respectively. The fluorescence quenching intensity for the other real samples was recorded and their percentages of recovery are summarized in Tables 3 and 4. The GSH-CDs displayed high selectivity and sensitivity for the $\mathrm{As}^{3+}$ and $\mathrm{ClO}^{-}$ions, even in the presence of other competing ions. The results clearly demonstrated that the GSH-CDs sensor is applicable for the practical analysis of $\mathrm{As}^{3+}$ and $\mathrm{ClO}^{-}$ions in real samples.

\section{Conclusions}

In conclusion, we developed facile, green, and low-cost GSHCDs through a one-pot hydrothermal route using a prickly pear cactus as a carbonization source for fluorescent CDs. In addition, the surface passivation arises from the effect of glutathione used to improve the surface functional groups, leading to enhanced sensitivity and selectivity. The improved fluorescence signaling performance of CDs via an inner filter effect was exploited in the recognition of $\mathrm{As}^{3+}$ or $\mathrm{ClO}^{-}$ions. Thus, the quenching of the emission intensity led to a linear response for a detection limit of the assay as low as $2.3 \mathrm{nM}$ for $\mathrm{As}^{3+}$ and $0.016 \mu \mathrm{M}$ for $\mathrm{ClO}^{-}$in drinking water samples. Moreover, the selectivity of the dual sensor was achieved by using L-cysteine and $\mathrm{NaBH}_{4}$ as masking agents to recover the $\mathrm{As}^{3+} / \mathrm{ClO}^{-}$ions. We envisage that this novel assay, with its simplicity, inexpensive nature, water solubility, and photostability of the carbon dots, could be used as a fluorescent sensing probe with superior performance over other chemical sensors. The obtained results validated that the GSH-CDs have good potential for real sample analysis.

\section{Conflicts of interest}

There are no conflicts to declare. 


\section{Acknowledgements}

This work was supported by SRM Institute of Science and Technology, Department of Chemistry, Tamilnadu, India.

\section{References}

1 S. K. Pal, N. Akhtar and S. K. Ghosh, Anal. Methods, 2016, 8, 445-452.

2 A. Dhillon, M. Nair and D. Kumar, Anal. Methods, 2015, 7, 10088-10108.

3 X. Liu, W. Zhang, Y. Hu, X. Xie, L. Wang and H. Cheng, Chemosphere, 2015, 119, 273-281.

4 K. Chauhani, P. Singhi, B. Kumari and R. K. Singhal, Anal. Methods, 2017, 9, 1779-1785.

5 N. Yogarajaha and S. S. H. Tsai, Environ. Sci.: Water Res. Technol., 2015, 1, 426-447.

6 G. Zhou, H. Pu, J. Chang, X. Sui, S. Mao and J. Chena, Sens. Actuators, B, 2018, 257, 214-219.

7 V. C. Ezeh and T. C. Harrop, Inorg. Chem., 2012, 51, 12131215.

8 M. M. Moriarty, I. Koch and K. J. Reimer, Environ. Sci.: Processes Impacts, 2013, 15, 1520-1528.

9 A. Manna, D. Sarkar, S. Goswami, C. K. Quah and H. Fun, RSC Adv., 2016, 6, 57417-57423.

10 Y. Guo, L. Zhang, F. Cao, L. Mang, X. Lei, S. Cheng and J. Song, Anal. Methods, 2016, 8, 2723-2728.

11 J. H. T. Luong, E. Lam and K. B. Male, Anal. Methods, 2013, 42, 6157-6169.

12 J. H. An and J. Jang, Nanoscale, 2017, 9, 7483-7492.

13 S. Goswami, S. Paul and A. Manna, Dalton Trans., 2013, 42, 10097-10101.

14 M. Ren, K. Zhou, L. He and W. Lin, J. Mater. Chem. B, 2018, 6, 1716-1733.

15 L. Pang, Y. Zhou, W. Gao, H. Song, X. Wang and Y. Wang, RSC Adv., 2016, 6, 105795-105800.

16 I. B. Zavodnik, E. A. Lapshina, L. B. Zavodnik, M. Soszynski, G. Bartosz and M. Bryszewska, Bioelectrochemisty, 2002, 58, 127-135.

$17 \mathrm{~J} . \mathrm{Li}, \mathrm{F}$. Huo and C. Yin, $R S C A d v ., 2014,4$, 44610-44613.

18 X. Lou, Y. Zhang, Q. Li, J. Qin and Z. Li, Chem. Commun., 2011, 47, 3189-3191.

19 N. Yadav and A. K. Sing, RSC Adv., 2016, 6, 100136-100144.

20 S. Lohar, S. Pal, B. Sen, M. Mukherjee, S. Banerjee and P. Chattopadhyay, Anal. Chem., 2014, 86, 11357-11361.

21 X. Guo, B. Chen, M. He, B. Hu and X. Zhou, J. Anal. At. Spectrom., 2013, 28, 1638-1647.

22 K. Ito, C. D. Palmer, A. J. Steuerwaldab and P. J. Parsons, J. Anal. At. Spectrom., 2010, 25, 1334-1342.

23 J. L. Gomez-Ariza, D. Sanchez-Rodas and I. Giraldez, J. Anal. At. Spectrom., 1998, 13, 1375-1379.

24 C. Yuan, K. Zhang, Z. Wang and G. Jiang, J. Anal. At. Spectrom., 2010, 25, 1605-1611.

25 S. Arpadjan, L. Vuchkova and E. Kostadinova, Analyst, 1997, 122, 243-246.

26 S. Lin, W. Wang, C. Hu, G. Yang, C. Ko, K. Ren, C. Leung and D. Ma, J. Mater. Chem. B, 2017, 5, 479-484.
27 P. Karthik, A. Pandikumar, M. Preeyanghaa, M. Kowsalya and B. Neppolian, Microchim. Acta, 2017, 187, 2265-2273.

28 Y. Wu, S. Zhan, F. Wang, L. He, W. Zhi and P. Zhou, Chem. Commun., 2012, 48, 4459-4461.

29 P. Nath, R. K. Arun and N. Chandan, $R S C A d v ., 2014$, 4, 59558-59561.

30 M. Sun, H. Yu, H. Zhu, F. Ma, S. Zhang, D. Huang and S. Wang, Anal. Chem., 2014, 86, 671-677.

31 F. Wei, Y. Lu, S. He, L. Zhao and X. Zeng, Anal. Methods, 2012, 4, 616-618.

32 W. Lin, L. Long, B. Chen and W. Tan, Chem.-Eur. J., 2009, 15, 2305-2309.

33 X. Lou, Y. Zhang, J. Qin and Z. Li, Sens. Actuators, B, 2012, 161, 229-234.

34 K. Shanmugaraj and M. Ilanchelian, New J. Chem., 2017, 41, 14130-14136.

35 X. Niu, G. Liu, L. Li, Z. Fu, H. Xu and F. Cui, $R S C A d v ., 2015$, 5, 95223-95229.

36 R. R. Gaddam, D. Vasudevan, R. Narayan and K. V. S. N. Raju, RSC Adv., 2014, 4, 57137-57143.

37 L. Li, D. Yin, K. Xu, Y. Liu, D. Song, J. Wang, C. Zhao, X. Song and J. Li, J. Pharm. Biomed. Anal., 2017, 141, 79-86.

38 C. Cheng, Y. Shi, M. Li, M. Xing and Q. Wu, Mater. Sci. Eng. Carbon, 2017, 79, 473-480.

39 B. C. M. Martindale, G. A. M. Hutton, C. A. Caputo and E. Reisner, J. Am. Chem. Soc., 2015, 137, 6018-6025.

40 X. Yue, T. Chun-Jing, H. Hong, S. Chao-Qun, Z. Ya-Kun, Y. E. Qun-Feng and W. Ai-Jun, Chin. J. Anal. Chem., 2014, 42, 1252-1258.

41 X. Gao, C. Du, Z. Zhuang and W. Chen, J. Mater. Chem. C, 2016, 4, 6927-6945.

42 J. Ju, R. Zhang and W. Chen, Sens. Actuators, B, 2016, 228, 6673.

43 Z. Li, Y. Zhang, Q. Niu, M. Mou, Y. Wu, X. Liu, Z. Yan and S. Liao, J. Lumin., 2017, 187, 274-280.

44 W. Lu, X. Qin, S. Liu, G. Chang, Y. Zhang, Y. Luo, A. M. Asiri, A. O. Al-Youbi and X. Sun, Anal. Chem., 2012, 84, 5351-5357.

45 A. M. Aslandas, N. Balci, M. Arik, H. Sakiroglu, Y. Onganer and K. Meral, Appl. Surf. Sci., 2015, 356, 747-752.

$46 \mathrm{~S}$. Zhu, Y. Luo, Y. Feng, Y. Zhuo and Y. Dou, Biosens. Bioelectron., 2014, 60, 292-298.

47 R. Patidar, B. Rebary, G. R. Bhadua and P. Paula, J. Lumin., 2016, 173, 243-249.

48 J. Xu, Y. Zhou, S. Liu, M. Dong and C. Huang, Anal. Methods, 2014, 6, 2086-2090.

49 J. Xu, T. Lai, Z. Feng, X. Weng and C. Huang, Luminescence, 2015, 30, 420-424.

50 S. J. Zhu, Q. N. Meng, L. Wang, J. H. Zhang, Y. B. Song, H. Jin, K. Zhang, H. C. Sun, H. Y. Wang and B. Yang, Angew. Chem., Int. Ed., 2013, 52, 3953-3957.

51 F. F. F. Teles, J. W. Stull, W. H. Brown and F. M. Whiting, J. Sci. Food Agric., 1984, 35, 421-425.

52 B. De and N. Karak, RSC Adv., 2013, 3, 8286-8290.

53 D. Xiao, R. Pan, S. Li, J. He, M. Qi, S. Kong, Y. Gu, R. Lin and H. He, RSC Adv., 2015, 5, 2039-2046.

54 Y. Dong, G. Li, N. Zhou, R. Wang, Y. Chi and G. Chen, Anal. Chem., 2012, 84, 8378-8382. 
55 K. Vaisanav, J. Korram, P. Pradhan, K. Chandraker, R. Nagwanshi, K. K. Ghosh and M. L. Satnami, J. Fluoresc., 2017, 27, 781-789.

56 D. Pooja, S. Saini, A. Thakur, B. Kumar and S. Tyagi, J. Hazard. Mater., 2017, 328, 117-126.

57 X. Wang, Y. Lv and X. Hou, Talanta, 2011, 84, 382-386.

58 A. A. Ensafi, N. Kazemifard and B. Rezaei, Biosens. Bioelectron., 2016, 77, 499-504.

59 Y. Guo, L. Zhang, F. Cao, L. Mang, X. Lei, S. Cheng and J. Song, Anal. Methods, 2016, 8, 2723-2728.

60 T. Hallaj, M. Amjadi, J. L. Manzoori and R. Shokri, Microchim. Acta, 2015, 182, 789-796.

61 E. F. C. Simoes, J. M. M. Leitao and J. C. G. E. Da Silva, Microchim. Acta, 2016, 182, 1769-1777.
62 Y. Wang, P. Zhang, Q. Lu, Y. Wang, W. Fu, Q. Tang and W. Luo, Microchim. Acta, 2018, 185, 233-239.

63 Y. Ding, J. Ling, J. Cai, S. Wang, X. Li and M. Yang, Anal. Methods, 2016, 8, 1157-1161.

64 R. Zhang and W. Chen, Biosens. Bioelectron., 2014, 55, 83-90. 65 X. Gao, Y. Lu, R. Zhang, S. He, J. Ju, M. Liu, L. Li and W. Chen, J. Mater. Chem. C, 2015, 3, 2302-2309.

66 J. Ju and W. Chen, Anal. Chem., 2015, 87, 1903-1910.

$67 \mathrm{~J} . \mathrm{Ju}$ and W. Chen, Biosens. Bioelectron., 2014, 58, 219-225.

68 J. Ju, R. Zhang, S. He and W. Chen, RSC Adv., 2014, 4, 5258352589.

69 Y. Tang, Y. Su, N. Yang, L. Zhang and Y. Lv, Anal. Chem., 2014, 86, 4528-4535.

70 Y. Qin, H. Kwon, M. M. R. Howlader and M. J. Deen, RSC Adv., 2015, 5, 69086-69109. 